\title{
Influence of denaverine hydrochloride on calving ease in Holstein-Friesian heifers
}

\author{
K. Lange, W. Heuwieser, ${ }^{*}$ and C. Fischer-Tenhagen \\ Clinic for Animal Reproduction, Faculty of Veterinary Medicine, Freie Universität Berlin, Königsweg 65, 14163 Berlin, Germany
}

\begin{abstract}
Calving is assumed to be an exhausting and painful event. A drug that eases the calving procedure and alleviates pain would help cows, especially those suffering from dystocia. In a randomized, controlled, and blinded trial, we measured the effect of denaverine hydrochloride on physical and physiological calving parameters. Eighty-three Holstein-Friesian heifers were included in the analysis. Pulling force was measured using a digital force gauge interposed between the calf and a mechanical calf puller. The concentration of cortisol was measured in serum before and after parturition. There was no effect of treatment group on calving modality (i.e., spontaneous vs. assisted calving), duration of calving, and cortisol concentration. The area under the curve of pulling force $\times$ time $(\mathrm{n}=44)$, however, was significantly smaller in the treatment group compared with the placebo group. Also, duration of calving assistance was numerically shorter in the treatment group compared with the placebo group. The results provide evidence that calving ease can be influenced by denaverine hydrochloride during calving assistance.
\end{abstract}

Key words: pulling force, calving ease, pain, obstetric

\section{INTRODUCTION}

Optimal calving management is important to control dystocia in dairy cows (Mee, 2008). Dystocia, defined as difficult calving, caused by a prolonged calving or severe assisted extraction (Mee, 2004) is associated with negative consequences for the dam [i.e., increased risk for metritis (Dubuc et al., 2010), decreased fertility (Tenhagen et al., 2007), and economic losses (Dematawewa and Berger, 1997)] and for the calf (e.g., stillbirth, respiratory and digestive disease; Lombard et al., 2007). Calving is described as a painful procedure (Mainau and Manteca, 2011). A survey answered by 641 cattle practitioners in the United Kingdom dem-

Received April 17, 2018.

Accepted January 29, 2019.

*Corresponding author: w.heuwieser@fu-berlin.de onstrated that dystocia is perceived as one of the most painful conditions in adult cattle (Huxley and Whay, 2006). Heifers especially suffer due to a prolonged calving duration with higher effort (Noakes et al., 2001) and a higher incidence of dystocia in contrast to multiparous cows (Funnell and Hilton, 2016). In a recent survey, animal welfare was the primary issue raised by consumers regarding dairy farming (Cardoso et al., 2016). According to US and German animal welfare acts, it is mandatory to avoid pain, suffering, and harm in animals (BMJV, 2017; USDA, 2017). For farm animals, the "5 freedoms" were developed as objectives for animal welfare (Farm Animal Welfare Council, 1993).

Pain evaluation in cattle is challenging and has been studied with different approaches (Dyer et al., 2007; Heinrich et al., 2010; Huber et al., 2013). Recently, the first evidence for pain evaluation based on head and ear position, attention, response to approach, facial expressions, and back position was presented (Gleerup et al., 2015). In an experiment with 96 cows, the pain score of diseased cows decreased after treatment with an analgesic, whereas the score of control animals remained constant after treatment (Gleerup et al., 2015). In farm animals, physiological reactions such as the release of glucocorticoids (Mormède et al., 2007), the change of heart rate variability (von Borell et al., 2007; Nagel et al., 2016b), or the varying composition of immune cells (Caroprese et al., 2010) were used to evaluate stress. For acute stress responses, cortisol concentrations in blood plasma, serum (Negrão et al., 2004; Civelek et al., 2008; Saco et al., 2008), or saliva (Barrier et al., 2013; Nagel et al., 2016a) have been measured in farm animals. Cortisol concentration in blood serum was measured during this study to measure the heifers' stress during parturition. Cortisol was measured in serum because blood is easy to obtain. Furthermore, cortisol is an established substance for stress measurement in farm animals (Mormède et al., 2007; Huzzey et al., 2011). Alternative materials such as urine, milk, saliva, and feces were discussed beforehand but disregarded. Sampling techniques would have required more handling or more frequent sampling intervals (Möstl and Palme, 2002; Mormède et al., 2007). 
Substance $\mathrm{P}$ is a neuropeptide that is involved in the regulation of pain in animals (Coetzee, 2011). In veterinary medicine, it is determined in blood plasma to examine pain reactions to presumably painful procedures such as castrations or electroejaculation (Coetzee et al., 2008; Whitlock et al., 2012; Dockweiler et al., 2013). As this parameter is less common than cortisol measurement, we decided to examine the latter due to reasons of comparability.

Prevalence of calving assistance ranges between $10 \%$ and more than $50 \%$ worldwide (Mee, 2008). Lombard et al. (2007) analyzed more than 7,000 calvings from 3 Colorado dairy farms and found that more than $50 \%$ of the calves born to primiparous dams were delivered with assistance. Assisted calvings can result in vulvovaginal laceration and retained placenta (Kovács et al., 2016). Vulvovaginal lacerations occurred in 18.8 and $80 \%$ of the cows that experienced appropriately timed assistance and premature assistance (i.e., <65 min after the appearance of the fetal hooves), respectively. In contrast, vulvovaginal lacerations were found in none of the cows that calved spontaneously in a group pen and in $9.5 \%$ of the cows that calved spontaneously in an individual pen (Kovács et al., 2016). Calving difficulty may negatively influence milk production and saleable milk yields (Barrier and Haskell, 2011). Furthermore, calves that experience dystocia suffer from higher stress, reduced transfer of passive immunity, and higher morbidity and mortality (Tenhagen et al., 2007; Barrier et al., 2013).

Sensiblex (denaverine hydrochloride, DNH; VeyxPharma, Schwarzenborn, Germany) is currently approved to treat dystocia in dairy cows and dogs in several European Union (e.g., Bulgaria, France, Germany, Ireland, Italy, Poland, Spain, and United Kingdom) and non-European Union (e.g., Egypt, Mexico, Russia, Turkey, and Ukraine) countries. This drug improves the elasticity of the soft birth canal and regulates labor contractions (Veyx-Pharma GmbH, 2009). In addition, a certain analgesic effect was described in mice (Hüller, 1970). In a recent study, a positive effect of a combination of DNH (400 mg i.m. once or twice) and $0.35 \mathrm{mg}$ of oxytocin in a long-acting formulation (carbetocin, i.m. once or twice) on calving ease and postpartum reproductive health was found (Zobel and Taponen, 2014). Unfortunately, the study was not blinded and the manual estimation of the opening of the vulva and cervix must be considered to be confounded due to subjectivity. Efficacy of DNH alone has not yet been evaluated. Denaverine hydrochloride is approved to ease calving specifically in heifers. Dystocia occurs more frequently in primiparous dams compared with multiparous dams (Lombard et al., 2007); primiparous dams were there- fore chosen as the study population. Furthermore, we aimed to have a consistent study population.

Interestingly, science-based information on measuring pulling force during calving assistance is scarce. Becker et al. (2010) developed an in vitro model to measure and compare forces during calving assistance with different pulling techniques. Until the entry of the elbows into the pelvis, maximum force on 1 leg measured during simultaneous traction was $431 \pm 127$ N. During alternate traction, maximum values were $411 \pm 86 \mathrm{~N}$ with a difference in traction of $5 \mathrm{~cm}$ and $341 \pm 106 \mathrm{~N}$ with a difference of $10 \mathrm{~cm}$ between both legs. The latter value differed from the measured force of simultaneous traction $(P \leq 0.01)$. In another in vivo study, pulling force was measured in 24 calvings using a mechanical calf puller and a computer-controlled system (Wehrend et al., 2003). The authors categorized the pulling forces into light $(\sim 490 \mathrm{~N}$, duration: $41 \pm 21 \mathrm{~s})$, moderately heavy ( 784-981 N, duration: $86 \pm 22 \mathrm{~s})$, and heavy ( 981-1,177 N, duration: $268 \pm 117 \mathrm{~s})$ pulling force. In 2 cases lesions were found after moderately heavy force, and in 5 cases lesions occurred after heavy pulling force was applied. Maximum values of up to $1,471 \mathrm{~N}$ were recorded.

To our knowledge, a randomized controlled trial investigating the efficacy of DNH considering calving ease (i.e., pulling force and duration of parturition) has not yet been conducted. Therefore, the objective of this study was to evaluate the efficacy of DNH in heifers during parturition. Specifically, we set out to evaluate pulling force in parturitions to determine duration of parturitions and to compare cortisol concentration before and after parturition in heifers treated with $\mathrm{DNH}$ and a placebo.

\section{MATERIALS AND METHODS}

\section{Animals and Housing}

The study was conducted on a commercial dairy farm in Sachsen-Anhalt, Germany, between June and November 2015. A total of 120 heifers were enrolled in the study on d $267 \pm 2$ postinsemination. Overall, 37 heifers $(30.8 \%)$ were excluded due to abnormal presentations, positions, or postures during parturition and oversized calves $(\mathrm{n}=8)$ or for not complying with the timeline of the study protocol $(\mathrm{n}=29)$. The timeline was abandoned when signs of premature expulsion of the placenta (i.e., expulsion of the placenta concurrently with the expulsion of the fetus) were visible and calves showed a considerably blue tongue and clear lingual edema, which necessitated a faster intervention to prevent risks for the calves. 
The remaining 83 Holstein-Friesian heifers (age: $757 \pm 71 \mathrm{~d}$; BW: $670 \pm 55 \mathrm{~kg}$ ) were included in the analyses. Heifers in the last month of pregnancy were housed in a freestall barn with slatted floors and stalls bedded with recycled manure solids. Heifers were fed a TMR. The rations were formulated to meet or exceed NRC (2001) requirements. Feed was delivered over a conveyer belt system 10 times per day. Approximately 3 to $5 \mathrm{~d}$ before the estimated calving date, heifers were brought to a freestall facility with deep-bedded straw serving as a calving pen. A TMR was fed once a day at approximately $0700 \mathrm{~h}$ and pushed up 8 times per day. All cows had access to water ad libitum.

\section{Experimental Design}

Heifers in the precalving pen were enrolled on d 267 \pm 2 postinsemination. On this day a clinical examination was performed, including pulse at the arteria coccygea mediana, respiratory rate, and rectal temperature. Furthermore, body condition was scored and BW was measured with a weight measuring tape (Topagrar, Landwirtschaftsverlag GmbH, Münster, Germany). This examination was conducted to ensure that heifers were without pathological findings.

Blood sampling was conducted at enrollment and at weekly intervals. For analyses, the last measurement before calving (i.e., before the heifer was brought to the calving pen) was compared with the measurement directly after calving. Blood samples were drawn from the coccygeal vein with an evacuated tube system (Vacuette 8-mL Serum Beads Clot Activator, Greiner BioOne GmbH, Kremsmünster, Austria) with an 18-gauge needle to examine cortisol concentration. Pregnancy was confirmed by transrectal palpation. Swelling and edema of the vulva, the relaxation of the broad pelvic ligaments, the enlargement of the udder, and the filling of the rear teats were evaluated on a 4-point scale according to Streyl et al. (2011). After this initial examination, enrolled heifers in the precalving pen were examined once per day to evaluate relaxation of the pelvic ligaments and filling of the rear teats. The aim of this examination was to exclude the possibility of calving in the next $24 \mathrm{~h}$ as described in a previous study (Streyl et al., 2011). Approximately 5 to $3 \mathrm{~d}$ before calving, heifers were brought into the calving pen. In the calving pen, evaluation of the pelvic ligaments and examination of the rear teats were conducted twice daily at 0800 and 2000 h. Heifers in the calving pen were observed hourly via direct observation of 1 trained investigator. Additionally, video surveillance was conducted $24 \mathrm{~h} / \mathrm{d}$. The video recordings were used to determine the time of the appearance of the calves' feet, if this event could not be observed directly.
The study protocol to evaluate the influence of DNH (Sensiblex) on calving ease started with the first appearance of the fetal claws outside the vulva, which was considered to be the beginning of stage 2 of labor. Thirty minutes later, $400 \mathrm{mg}$ of $\mathrm{DNH}$ (i.e., $10 \mathrm{~mL}$ of Sensiblex) or placebo (PLA; i.e., $10 \mathrm{~mL}$ of $0.9 \% \mathrm{NaCl}^{-}$; B. Braun, Melsungen, Germany) was administered to the heifer subcutaneously. Both substances were clear and had a similar viscosity. Assignment to the 2 treatment groups was randomized using a randomization list generated with Microsoft Excel (version 2013; Microsoft Corp., Redmond, WA) before the study and blinded to the investigator. The time interval of $30 \mathrm{~min}$ after the onset of stage 2 of calving was chosen according to the specific product characterization. If the heifer calved spontaneously within 30 min after application (i.e., 60 min after onset of stage 2), calving was categorized as unassisted. Calving was defined as the passage of the calf in anterior presentation and dorsal position through the vulva until both tarsal joints were visible outside the dam. If both forelegs of the calf and the head with both eyes were visible outside the vulva 30 min after treatment, the heifer was allowed to continue calving without intervention and was categorized as unassisted as well. If the calf was not born 30 min after treatment, an extraction of the calf was conducted. First, the heifer's anogenital region was cleaned with warm water and soap and a vaginal examination was carried out to rule out any malposition or inappropriate size of the calf. In both cases the heifer was excluded from the study. Without exception, all extractions were conducted in a lying position of the dam. If the heifer was standing the animal was cast first. Two female veterinarians and 1 member of the farm staff were involved in the pulling process. One veterinarian was responsible for the heifer, another veterinarian operated the force gauge, and 1 farm employee used the mechanical calf puller at the veterinarian's instructions. As soon as the heifer was lying in a sternal position, a mechanical calf puller was positioned behind the heifer. One calving rope with 2 loops on each end was attached to the calf's feet. A digital force gauge (PCE-FB2 k, PCE Deutschland $\mathrm{GmbH}$, Meschede, Germany; Figure 1) was interposed between the ends of the calving rope and the mechanical calf puller using 2 carabiners. The calf puller was used with a constant tension; actual pulling was performed only when the heifer strained. The force gauge used for this study measured the pulling force 2 times per second starting with the first pull on the ropes with an accuracy of $\pm 0.1 \%$ (up to 2,000 $\mathrm{N}$ ). Results were continuously recorded on a secure digital memory card. Measurement ended when the calf was completely delivered. On average $3.0 \pm 4.4$ min after calving (i.e., unassisted or assisted calving), 


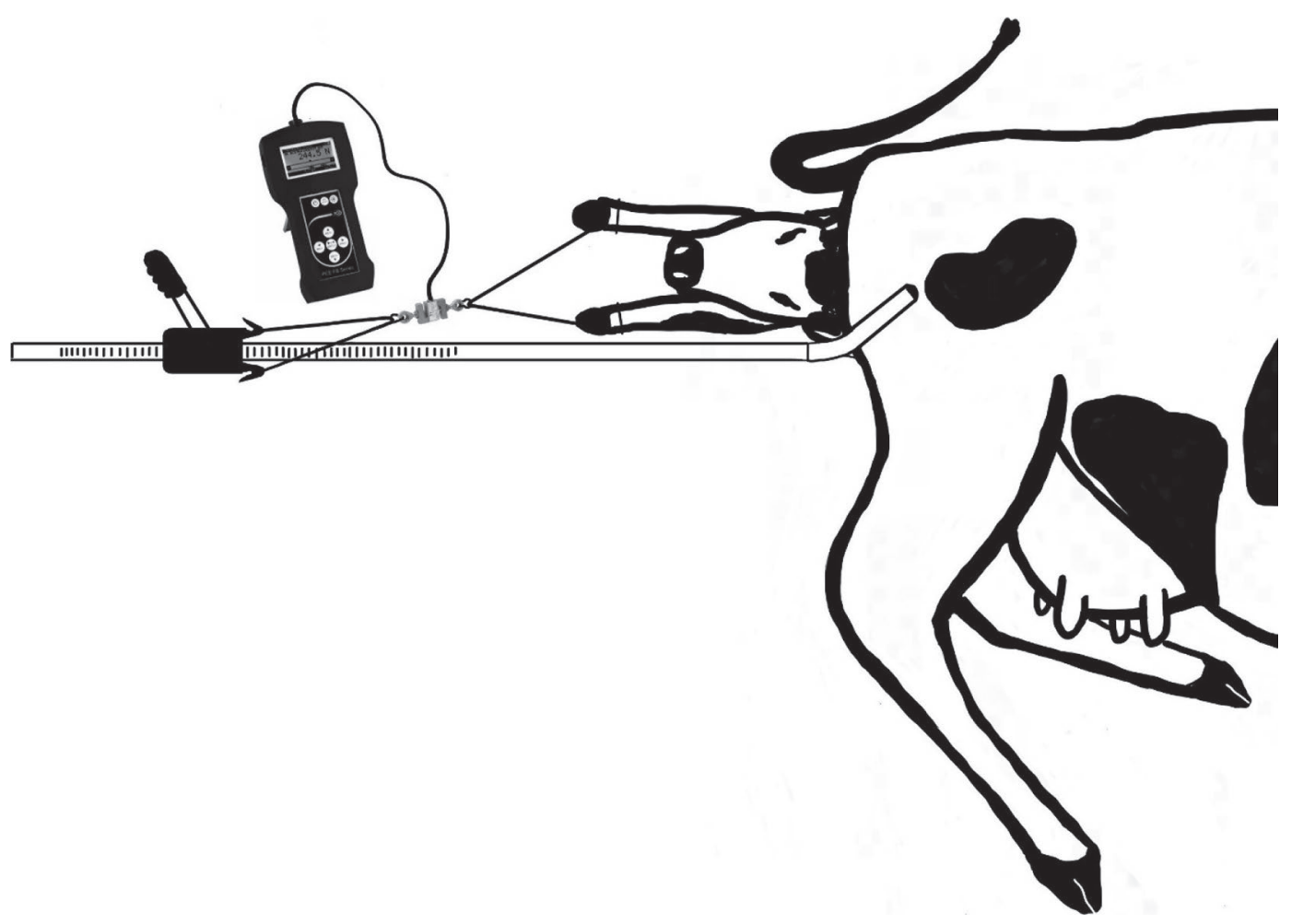

Figure 1. Use of calf puller and force gauge interposed between the calf's feet and the mechanical calf puller during calving assistance.

a blood sample was taken from the heifer's coccygeal vein using an evacuated tube system (Vacuette $8 \mathrm{~mL}$ Serum Beads Clot Activator, Greiner Bio-One GmbH). Blood samples were centrifuged at 3,000 $\times g$ for 10 min at room temperature and serum was stored at $-22^{\circ} \mathrm{C}$ until analysis for cortisol concentration. Furthermore, after an assisted calving, a vaginal examination was carried out to identify calving trauma. An obstetrical examination was performed when the newborn calf was small to exclude the possibility of twins. Finally, the calf was tube fed with $3 \mathrm{~L}$ of colostrum. Dam and calf were separated and brought to a postpartum pen and a calf box, respectively.

Personal perception of calving ease was rated by 2 veterinarians on a 4-point scale (i.e., very easy, easy, difficult, very difficult). Serum samples were analyzed for cortisol concentration at a commercial laboratory (Synlab Laboratories, Berlin, Germany; accreditation number D-PL-14016-01-00; accreditation body: DAkkS, Berlin, Germany) using an immunoassay based on chemiluminescence. We aimed to exclude risk factors that could confound the calving process. Abnormal presentation, position, or posture lead to necessary corrective action. Due to animal welfare considerations, integrity and vitality of calf and dam were our priority. If the time protocol was not met, the calving was excluded. We modified the classification of Wehrend et al. (2003) such that light pulling force ranged from 0 to $500 \mathrm{~N}$, moderately heavy force from 501 to 1,000 $\mathrm{N}$, and heavy pulling force from $1,001 \mathrm{~N}$ to include all measured results.

\section{Statistical Analysis}

Data were entered into Excel spreadsheets (version 2013; Microsoft Corp.) and analyzed using SPSS for Windows (version 22.0; SPSS Inc., Munich, Germany). The area under the curve (AUC) enables statistical comparison between groups without comparing every single value separately (Kovács et al., 2014). The intensity and the changes over time can be described through the AUC (Fekedulegn et al., 2007). For pulling force over time, the AUC was calculated with the pulling force displayed on the $\mathrm{x}$-axis and the measured time in seconds on the y-axis. Normality of distributions of continuous parameters (i.e., force $\times$ time, cortisol concentration, and duration of calving) was assessed by plotting and visually examining the data, calculating a quantile-quantile plot, and using the Shapiro-Wilk test. Equality of variances was determined using Levene's test. The association between duration of calving considering both unassisted and assisted calving ( $\mathrm{n}=$ 
83) and the difference in cortisol concentration before and after parturition was determined using the Pearson correlation coefficient.

Generalized linear mixed models were used to determine the effect of treatment group, day of gestation, and birth weight of calves on force $\times$ time, the duration of the pulling, the duration of calving, and the concentration of cortisol in the heifer, respectively. All models were built in a backward stepwise manner according to the model-building strategies provided by Dohoo et al. (2009). Heifer was considered as a random effect. Interactions were tested for all relevant parameters. The covariate structure was chosen based on the lowest Akaike information criterion value. Post hoc comparison was carried out applying LSD test. Treatment group was considered as the factor of interest for all models and was forced to remain in the model regardless of level of significance until all nonsignificant parameters were removed.

A binary logistic regression model was built to determine the effect of treatment on the calving modality (i.e., unassisted or assisted calving). The model was built again in a manual backward stepwise manner and according to the model-building strategies provided by Dohoo et al. (2009). Odds ratios and confidence intervals were calculated for all significant parameters. Again, treatment was forced to remain in the model. Finally, the influence of treatment group on the evaluation of calving through both obstetricians was calculated with the chi-squared test. For all tests, differences with $P<0.05$ were considered statistically significant.

\section{RESULTS}

Initially, 120 heifers were enrolled in the study. Data from 83 calvings ( 38 female calves, 45 male calves) were available for final analyses. Denaverine hydrochloride and PLA were administered to 41 and 42 heifers, respectively. Thirty-six heifers calved without assistance, and 47 heifers required calving assistance according to the study protocol. A total of 37 heifers $(30.8 \%)$ had to be excluded due to abnormal presentation, position, or posture of the calves (i.e., posterior presentation, lateral or ventral position, $\mathrm{n}=6$ ), oversized calves (i.e., cesarean section, $\mathrm{n}=2$ ), and failure to implement the underlying timeline (i.e., calving before administering of DNH or PLA, earlier intervention necessary because of a premature expulsion of the placenta, $\mathrm{n}=29$ ). In 3 calvings $(7 \%)$, data of pulling force could not be obtained due to technical failure of the force gauge. Hence, they were excluded from the analysis of pulling force. The duration of calving was measured and included in the analysis. Mean birth weight of calves was $41 \pm 4.6$ kg (range: $28-52 \mathrm{~kg}$ ).
A sample size calculation was performed before initiation of the study ( $\mathrm{G}^{*}$ Power, version 3.1.5; University of Düsseldorf, Düsseldorf, Germany). A difference of AUC (time $\times$ force) between both treatment groups was found in a pilot trial. Using $\alpha=0.05,1-\beta=$ 0.8 , and a 2-tailed study design, a sample size of 51 heifers per treatment group was necessary to verify our hypothesis.

Twenty out of 41 heifers treated with DNH (49\%) and 16 out of 42 heifers treated with PLA (38\%) calved without assistance. There was no effect of treatment on calving modality $(P=0.524)$. The duration of pregnancy had a Picant influence on calving assistance $(P$ $=0.016$, odds ratio: $0.846 ; 95 \%$ CI: $0.738-0.970$ )

The average duration of unassisted calving in the DNH and PLA groups was $57 \min 48 \mathrm{~s} \pm 13 \min 36$ $\mathrm{s}(\mathrm{n}=20)$ and $49 \min 48 \mathrm{~s} \pm 16 \min 30 \mathrm{~s}(\mathrm{n}=16)$, respectively $(P=0.119)$. The average duration for all calvings (i.e., assisted and unassisted) was $66 \mathrm{~min} 42$ $\mathrm{s} \pm 14 \min 54 \mathrm{~s}(\mathrm{n}=41)$ and $66 \min 48 \mathrm{~s} \pm 17 \mathrm{~min}$ $36 \mathrm{~s}(\mathrm{n}=42)$ for DNH and PLA heifers, respectively $(P=0.959)$. Calving assistance tended to be shorter in heifers treated with DNH $(3 \min 11 \mathrm{~s} \pm 1$ min 47 s) compared with PLA $(3 \min 59 \mathrm{~s} \pm 3 \min 5 \mathrm{~s} ; P$ $=0.075)$. The maximum pulling force measured was 1,979.5 N. Duration of pulling ranged from 1 to $12 \mathrm{~min}$. Average duration was $3.64 \pm 2.61 \mathrm{~min}$.

The AUC was $64,373 \pm 50,514 \mathrm{Ns}$ (i.e., $\mathrm{N} \times \mathrm{s}$ ) in the DNH group and $91,553 \pm 61,886 \mathrm{Ns}$ in the PLA group $(P=0.035$; Figure 2$)$. The AUC comprises time $\times$ pulling force, which means both parameters are converted into one dimension to facilitate comparability. Figure

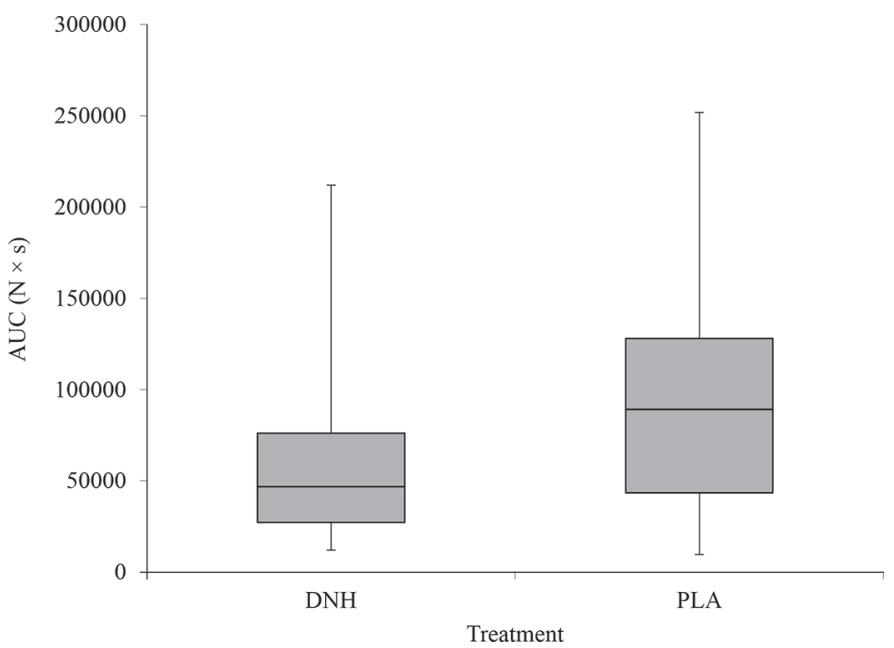

Figure 2. Boxplots of area under the curve $(A U C ; N \times s)$ in the denaverine hydrochloride (DNH) and placebo (PLA) groups. The central box represents the interquartile range from the first to third quartiles. A segment inside the box shows the highest or lowest case within 1.5 times the interquartile range. 
3 illustrates an example of pulling force measurement during calving assistance of 1 heifer.

A total of 166 cortisol samples (i.e., 1 sample before and 1 sample after calving of every heifer) were analyzed. The difference in cortisol concentration before and after parturition ranged from -4.61 to $210.34 \pm$ $6.86 \mathrm{nmol} / \mathrm{L}$ in the DNH group and 0.8 to $174.92 \pm 6.37$ $\mathrm{nmol} / \mathrm{L}$ in the PLA group. Mean difference in cortisol concentration before and after parturition regardless of treatment group was $105.8 \pm 43.45 \mathrm{nmol} / \mathrm{L}$. No effect of treatment was found on the increase of blood cortisol after parturition $(P=0.257)$. Cortisol differences were not correlated with duration of calving $(\mathrm{r}=0.025 ; P$ $=0.819)$ or force $\times$ time $(\mathrm{r}=0.059 ; P=0.703)$. In addition, there was no influence of treatment group on calving ease score $(P=0.284)$.

\section{DISCUSSION}

In this study, the effect of DNH on calving ease in heifers was tested. A drug with the label claim of easing calving is promising but also requires caution because it might lead to a reduced perception of the importance of timely and correct calving assistance. Therefore, proving efficacy is of paramount importance. Measuring calving ease, however, was challenging because the process of calving is dependent on many factors (i.e., calf birth weight, maternal age and pelvis size, calving pen) and difficult to standardize. Because we assumed that duration of stage 2 could influence the calving progress and thus modify the effect of a given pulling force during assistance, we set out to keep the time of treatment administration in our study relative to the beginning of stage 2 constant (i.e., $30 \mathrm{~min}$ after onset of stage 2). Therefore, onset of calving was monitored by direct observation and $24-\mathrm{h}$ video surveillance. A total of 83 heifers could be included in the analysis. A considerable number of heifers had to be excluded because it was impossible to meet the study protocol. Ten heifers calved in less than 30 min after the appearance of the calves' feet. In 19 heifers, we had to intervene before the 60-min limit was reached because the calf was at risk as indicated by a considerably blue tongue and clear lingual edema or premature placental expulsion. This study took place on a commercial dairy farm. For reasons of standardization, this might have been advantageous. Nevertheless, future studies should implement different farms to increase external validity.

We decided to inject DNH or PLA 30 min after onset of stage 2 and to allow the heifer a total of $60 \mathrm{~min}$ for giving birth unassisted. Schuenemann et al. (2011) measured a duration of $45.8 \mathrm{~min}$ for heifers from the appearance of the amniotic sac outside the vulva (i.e., indicative of stage 2 of calving) until birth of the calf in unassisted calvings. The authors recommend starting calving assistance $65 \mathrm{~min}$ after the appearance of the feet. A nonsystematic review reported that calving assistance $<60 \mathrm{~min}$ after the appearance of the fetal hooves increased the risk of using a calf puller, duration of assistance, dystocia, and downer cows and reduced perinatal vigor (Mee, 2008). More recently, a high prevalence of retained placenta $(78.9 \%)$ and vulvovaginal

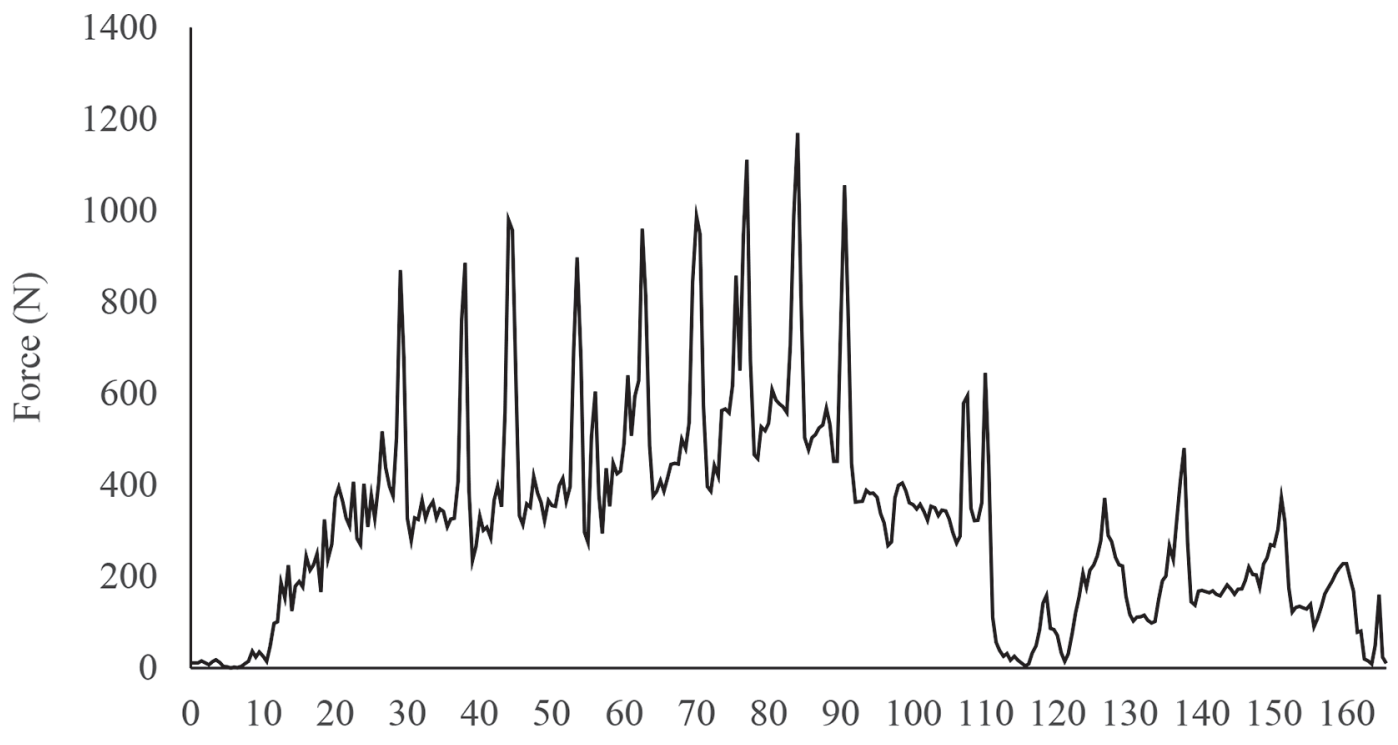

Time (s)

Figure 3. An example of force measurement during calving assistance of a heifer. 
lacerations $(80 \%)$ occurred in dams that experienced premature assistance (Kovács et al., 2016). The authors defined premature assistance as assistance provided $<65$ min after the appearance of the fetal hooves in the vulva. Eventually, they started assistance between 22 and $64 \mathrm{~min}(34.6 \pm 10.5 \mathrm{~min})$ after the amniotic sac appeared. In 2 recently published papers, the influence of systematic early calving assistance on calf health and calf survival was investigated (Villettaz Robichaud et al., 2017a,b). The authors achieved better results regarding calf mortality with obstetrical assistance within $15 \mathrm{~min}$ after the appearance of a calf's feet compared with a cutoff of $60 \mathrm{~min}$. According to the manufacturer, DNH needs 15 to 30 min after injection until a spasmolytic effect occurs (Veyx-Pharma GmbH, 2009). Intervening in the calving process 60 min after the calf's feet appeared seemed to be a reasonable compromise between giving time for drug-mediated dilation without risking the negative effects of a prolonged calving.

There was no difference between both treatment groups in necessity of calving assistance. Presumably, the 60-min cutoff prevented or limited an effect of treatment. This hypothesis probably needs to be tested in another experimental setup. Furthermore, it must be considered that treatment with DNH eases the calving process but is not supposed to prevent calving assistance completely.

Usually, the degree of calving assistance is categorized based on subjective estimates (Hindson, 1978; Tenhagen et al., 2007) and is assessed on 3- to 5-point scales depending on the number of people and the extent of pulling (Meyer et al., 2001; Villettaz Robichaud et al., 2017a). Measuring pulling force with a technical device is more objective. In an in vitro model to simulate the extraction of calves, the maximum mean traction force ranged from $352 \pm 98 \mathrm{~N}$ to $597 \pm 150$ $\mathrm{N}$ depending on the traction technique (Becker et al., 2010). In this model, the calf was pulled through an isolated pelvis; thus, resistance due to the soft tissues of the birth canal was missing. Few studies have been published that systematically measured pulling force in the field. Wehrend et al. (2003) evaluated pulling force for assisted calvings conducted with a mechanical calf puller in 24 cows. Peak values of up to $1,471 \mathrm{~N}$ were measured. By applying the modified classification, $20 \%$ of the calvings were assisted using heavy pulling force in the study of Wehrend et al. (2003). This is contrary to our study, where only light and moderate force was applied. This different distribution in pulling force most likely was caused because $95 \%$ of the cows used by Wehrend et al. (2003) suffered from abnormal position, presentation, and posture, which could have interrupted the calving process and resulted in higher pulling force. We excluded cases of abnormal position, presentation, and posture to achieve a more uniform population. Furthermore, time from the onset of calving until the onset of calving assistance varied widely (up to $4 \mathrm{~h}$ ), which indicates that the calving process was probably pathologically prolonged.

The AUC for pulling force was smaller in the treatment group. This could indicate an effect of DNH such that the birth canal was softer and wider, thus easing the calving process. Additionally, we suppose that the intensity of the pulling process (i.e., the duration of friction within the birth canal) negatively affects ease of calving because friction causes injury and inflammation in the tissue. This is in line with a previous study in which DNH and carbetocin increased the number of animals with a birth canal dilated $>25 \mathrm{~cm}$ and decreased time from the first examination to delivery as well as the need for assistance (Zobel and Taponen, 2014). Additionally, fewer birth canal lesions were found in the treatment group (Zobel and Taponen, 2014).

To quantify pain-mediated stress during parturition (Nagel et al., 2016b), we measured the concentration of cortisol. The difference in cortisol concentration before and after parturition for every heifer was calculated because the difference of cortisol concentration before and after a stressful event can indicate the stress level in cows (Bertulat et al., 2013). Blood cortisol concentrations differed before and after parturition in both treatment groups. A difference, however, was not found between the treatment group and the control group. Civelek et al. (2008) described higher plasma cortisol concentrations in heifers with dystocia compared with heifers with eutocia. An increase in cortisol concentration after parturition was reported (Hydbring et al., 1999; Nagel et al., 2016b). The latter authors found a short-term increase in cortisol concentration, which was considered to be an acute stress response (Nagel et al., 2016b). We assume that this physiological activation of the hypothalamicpituitary-adrenal axis, either as part of the endocrine pathway or as an acute stress response, was stronger and superimposed an effect of DNH treatment. Also, it is possible that the production of cortisol is not directly related to pulling force.

Further research is warranted to evaluate the influence of DNH on duration of the calving process and other stress and pain parameters such as heart rate variability or substance P (Coetzee, 2011). Nevertheless, we conclude that DNH can reduce pulling force under field conditions if calving assistance is conducted but did not influence the cortisol response of the dam. Hence, careful and competent calving assistance is indispensable. 


\section{ACKNOWLEDGMENTS}

We greatly appreciate the support of Veyx-Pharma (Schwarzenborn, Germany) during the study. Furthermore, we gratefully thank the farm personnel of the dairy farm for the kind cooperation and for their patience and confidence demonstrated. Special thanks go to the staff of the Clinic for Animal Reproduction, Freie Universität Berlin, Germany, for their support during the practical part. Katrin Lange was partly funded by Tiergyn e.V. (Berlin, Germany).

\section{REFERENCES}

Barrier, A. C., and M. J. Haskell. 2011. Calving difficulty in dairy cows has a longer effect on saleable milk yield than on estimated milk production. J. Dairy Sci. 94:1804-1812.

Barrier, A. C., M. J. Haskell, S. Birch, A. Bagnall, D. J. Bell, J. Dickinson, A. I. Macrae, and C. M. Dwyer. 2013. The impact of dystocia on dairy calf health, welfare, performance and survival. Vet. J. 195:86-90.

Becker, M., G. Tsousis, M. Lupke, F. Goblet, C. Heun, H. Seifert, and H. Bollwein. 2010. Extraction forces in bovine obstetrics: An in vitro study investigating alternate and simultaneous traction modes. Theriogenology 73:1044-1050.

Bertulat, S., C. Fischer-Tenhagen, V. Suthar, E. Mostl, N. Isaka, and W. Heuwieser. 2013. Measurement of fecal glucocorticoid metabolites and evaluation of udder characteristics to estimate stress after sudden dry-off in dairy cows with different milk yields. J. Dairy Sci. 96:3774-3787.

BMJV (Bundesministerium für Justiz und Verwaltung). 2017. Tierschutzgesetz in der Fassung der Bekanntmachung vom 18. Mai 2006 (BGBl. IS. 1206, 1313), das zuletzt durch Artikel 141 des Gesetzes vom 29. März 2017 (BGBl. IS. 626) geändert worden ist.

Cardoso, C. S., M. J. Hotzel, D. M. Weary, J. A. Robbins, and M. A. von Keyserlingk. 2016. Imagining the ideal dairy farm. J. Dairy Sci. 99:1663-1671.

Caroprese, M., M. Albenzio, A. Marzano, L. Schena, G. Annicchiarico, and A. Sevi. 2010. Relationship between cortisol response to stress and behavior, immune profile, and production performance of dairy ewes. J. Dairy Sci. 93:2395-2403.

Civelek, T., H. A. Celik, G. Avci, and C. C. Cingi. 2008. Effects of dystocia on plasma cortisol and cholesterol levels in Holstein heifers and their newborn calves. Bull. Vet. Inst. Pulawy 52:649-654.

Coetzee, J. F. 2011. A review of pain assessment techniques and pharmacological approaches to pain relief after bovine castration: Practical implications for cattle production within the United States. Appl. Anim. Behav. Sci. 135:192-213.

Coetzee, J. F., B. V. Lubbers, S. E. Toerber, R. Gehring, D. U. Thomson, B. J. White, and M. D. Apley. 2008. Plasma concentrations of substance $\mathrm{P}$ and cortisol in beef calves after castration or simulated castration. Am. J. Vet. Res. 69:751-762.

Dematawewa, C. M. B., and P. J. Berger. 1997. Effect of dystocia on yield, fertility, and cow losses and an economic evaluation of dystocia scores for Holsteins. J. Dairy Sci. 80:754-761.

Dockweiler, J. C., J. F. Coetzee, L. N. Edwards-Callaway, N. M. Bello, H. D. Glynn, K. A. Allen, M. E. Theurer, M. L. Jones, K. A. Miller, and L. Bergamasco. 2013. Effect of castration method on neurohormonal and electroencephalographic stress indicators in Holstein calves of different ages. J. Dairy Sci. 96:4340-4354.

Dohoo, I. R., S. W. Martin, and H. Stryhn. 2009. Veterinary Epidemiologic Research. University of Prince Edward Island, Charlottetown, PEI, Canada.

Dubuc, J., T. F. Duffield, K. E. Leslie, J. S. Walton, and S. J. LeBlanc. 2010. Risk factors for postpartum uterine diseases in dairy cows. J. Dairy Sci. 93:5764-5771.
Dyer, R. M., N. K. Neerchal, U. Tasch, Y. Wu, P. Dyer, and P. G. Rajkondawar. 2007. Objective determination of claw pain and its relationship to limb locomotion score in dairy cattle. J. Dairy Sci. 90:4592-4602.

Farm Animal Welfare Council. 1993. Second Report on Priorities for Research and Development in Farm Animal Welfare. Ministry of Agriculture, Fisheries and Food, London, UK.

Fekedulegn, D. B., M. E. Andrew, C. M. Burchfiel, J. M. Violanti, T. A. Hartley, L. E. Charles, and D. B. Miller. 2007. Area under the curve and other summary indicators of repeated waking cortisol measurements. Psychosom. Med. 69:651-659.

Funnell, B. J., and W. M. Hilton. 2016. Management and prevention of dystocia. Vet. Clin. North Am. Food Anim. Pract. 32:511-522.

Gleerup, K. B., P. H. Andersen, L. Munksgaard, and B. Forkman. 2015. Pain evaluation in dairy cattle. Appl. Anim. Behav. Sci. $171: 25-32$.

Heinrich, A., T. F. Duffield, K. D. Lissemore, and S. T. Millman. 2010. The effect of meloxicam on behavior and pain sensitivity of dairy calves following cautery dehorning with a local anesthetic. J. Dairy Sci. 93:2450-2457.

Hindson, J. C. 1978. Quantification of obstetric traction. Vet. Rec. 102:327-332.

Huber, J., T. Arnholdt, E. Möstl, C. C. Gelfert, and M. Drillich. 2013. Pain management with flunixin meglumine at dehorning of calves. J. Dairy Sci. 96:132-140.

Hüller, H. 1970. Pharmakologie und Klinik von O-(2-Athylbutoxy)benzilsaure-2-dimethylaminoäthylesterhydrochlorid (= Spasmalgan). Zentralbl. Pharm. 109:23-27.

Huxley, J. N., and H. R. Whay. 2006. Current attitudes of cattle practitioners to pain and the use of analgesics in cattle. Vet. Rec. 159:662-668

Huzzey, J. M., D. V. Nydam, R. J. Grant, and T. R. Overton. 2011. Associations of prepartum plasma cortisol, haptoglobin, fecal cortisol metabolites, and nonesterified fatty acids with postpartum health status in Holstein dairy cows. J. Dairy Sci. 94:5878-5889.

Hydbring, E., A. Madej, E. MacDonald, G. Drugge-Boholm, B. Berglund, and K. Olsson. 1999. Hormonal changes during parturition in heifers and goats are related to the phases and severity of labour. J. Endocrinol. 160:75-85.

Kovács, L., F. L. Kézér, and O. Szenci. 2016. Effect of calving process on the outcomes of delivery and postpartum health of dairy cows with unassisted and assisted calvings. J. Dairy Sci. 99:7568-7573.

Kovács, L., J. Tőzsér, O. Szenci, P. Póti, F. L. Kézér, F. Ruff, G. Gábriel-Tőzsér, D. Hoffmann, M. Bakony, and V. Jurkovich. 2014. Cardiac responses to palpation per rectum in lactating and nonlactating dairy cows. J. Dairy Sci. 97:6955-6963.

Lombard, J. E., F. B. Garry, S. M. Tomlinson, and L. P. Garber. 2007. Impacts of dystocia on health and survival of dairy calves. J. Dairy Sci. 90:1751-1760.

Mainau, E., and X. Manteca. 2011. Pain and discomfort caused by parturition in cows and sows. Appl. Anim. Behav. Sci. 35:241-251.

Mee, J. F. 2004. Managing the dairy cow at calving time. Vet. Clin. North Am. Food Anim. Pract. 20:521-546.

Mee, J. F. 2008. Prevalence and risk factors for dystocia in dairy cattle: A review. Vet. J. 176:93-101.

Meyer, C. L., P. J. Berger, K. J. Koehler, J. R. Thompson, and C. G. Sattler. 2001. Phenotypic trends in incidence of stillbirth for Holsteins in the United States. J. Dairy Sci. 84:515-523.

Mormède, P., S. Andanson, B. Aupérin, B. Beerda, D. Guémené, J. Malmkvist, X. Manteca, G. Manteuffel, P. Prunet, C. G. van Reenen, S. Richard, and I. Veissier. 2007. Exploration of the hypothalamic-pituitary-adrenal function as a tool to evaluate animal welfare. Physiol. Behav. 92:317-339.

Möstl, E., and R. Palme. 2002. Hormones as indicators of stress. Domest. Anim. Endocrinol. 23:67-74.

Nagel, C., J. Aurich, L. Trenk, N. Ille, M. Drillich, W. Pohl, and C. Aurich. 2016a. Stress response and cardiac activity of term and preterm calves in the perinatal period. Theriogenology 86:14981505 . 
Nagel, C., L. Trenk, C. Aurich, N. Ille, M. Pichler, M. Drillich, W. Pohl, and J. Aurich. 2016b. Sympathoadrenal balance and physiological stress response in cattle at spontaneous and PGF(2 alpha)induced calving. Theriogenology 85:979-985.

Negrão, J. A., M. A. Porcionato, A. M. de Passille, and J. Rushen. 2004. Cortisol in saliva and plasma of cattle after ACTH administration and milking. J. Dairy Sci. 87:1713-1718.

Noakes, D. E., T. J. Parkinson, and G. C. W. England. 2001. Parturition and the care of parturient animals. Pages 155-187 in Arthur's Veterinary Reproduction and Obstetrics. 8th ed. W.B. Saunders, Oxford, UK.

NRC. 2001. Nutrient Requirements of Dairy Cattle. 7th rev. ed. Natl. Acad. Press, Washington, DC.

Saco, Y., M. Fina, M. Giménez, R. Pato, J. Piedrafita, and A. Bassols. 2008. Evaluation of serum cortisol, metabolic parameters, acute phase proteins and faecal corticosterone as indicators of stress in cows. Vet. J. 177:439-441.

Schuenemann, G. M., I. Nieto, S. Bas, K. N. Galvao, and J. Workman. 2011. Assessment of calving progress and reference times for obstetric intervention during dystocia in Holstein dairy cows. J. Dairy Sci. 94:5494-5501.

Streyl, D., C. Sauter-Louis, A. Braunert, D. Lange, F. Weber, and H Zerbe. 2011. Establishment of a standard operating procedure for predicting the time of calving in cattle. J. Vet. Sci. 12:177-185.

Tenhagen, B. A., A. Helmbold, and W. Heuwieser. 2007. Effect of various degrees of dystocia in dairy cattle on calf viability, milk production, fertility and culling. J. Vet. Med. A Physiol. Pathol Clin. Med. 54:98-102.

USDA. 2017. Animal Welfare Act and Animal Welfare Regulations. Accessed Mar. 28, 2018. https://www.aphis.usda.gov/
animal_welfare/downloads/AC_BlueBook_AWA_FINAL_2017 _508comp.pdf.

Veyx-Pharma Gmb, H. 2009. Fachinformation Sensiblex $40 \mathrm{mg} /$ mL. (Zulassungsnummer 3100278.00.00.) Veyx-Pharma GmbH, Schwarzenborn, Germany.

Villettaz Robichaud, M. V., D. L. Pearl, S. M. Godden, S. J. LeBlanc, and D. B. Haley. 2017a. Systematic early obstetrical assistance at calving: I. Effects on dairy calf stillbirth, vigor, and passive immunity transfer. J. Dairy Sci. 100:691-702.

Villettaz Robichaud, M. V., D. L. Pearl, S. M. Godden, J. Rushen, S. J. LeBlanc, and D. B. Haley. 2017b. Systematic early obstetrical assistance at calving: II. Effects on dairy heifer calf growth, health, and survival to weaning. J. Dairy Sci. 100:703-712.

von Borell, E., J. Langbein, G. Despres, S. Hansen, C. Leterrier, J. Marchant-Forde, R. Marchant-Forde, M. Minero, E. Mohr, A. Prunier, D. Valance, and I. Veissier. 2007. Heart rate variability as a measure of autonomic regulation of cardiac activity for assessing stress and welfare in farm animals - A review. Physiol. Behav. 92:293-316.

Wehrend, A., K. B. Padberg, and H. Bostedt. 2003. Electronic quantification of traction force during use of a mechanical calving aid in bovine parturition. Berl. Munch. Tierarztl. Wochenschr. 116:1219 .

Whitlock, B. K., E. A. Coffman, J. F. Coetzee, and J. A. Daniel. 2012. Electroejaculation increased vocalization and plasma concentrations of cortisol and progesterone, but not substance $\mathrm{P}$, in beef bulls. Theriogenology 78:737-746.

Zobel, R., and J. Taponen. 2014. Denaverine hydrochloride and carbetocin increased welfare during and after parturition and enhanced subsequent fertility in cattle. J. Dairy Sci. 97:3570-3577. 